\title{
BEM-ESTAR MULTIDIMENSIONAL: UMA COMPARAÇÃO ENTRE GRUPOS DE DOMICÍLIOS EM SITUAÇÃO DE POBREZA E VULNERABILIDADE
}

\author{
Izete Pengo Bagolin ${ }^{1}$ \\ Natália Lindemayer ${ }^{2}$ \\ Luana dos Santos Fraga ${ }^{3}$
}

Resumo: O objetivo deste artigo é comparar o bem-estar pessoal de beneficiários e não beneficiários do Programa Bolsa Família, que residem em domicílios bi ou monoparentais, podendo ser chefiados por homens ou mulheres. Para tal, é construído um Indicador Multidimensional de Bem-Estar (IMBE), empregando os microdados do Censo de 2010 utilizando uma metodologia similar à do Índice de Desenvolvimento Humano. Os resultados mostram que, em relação aos beneficiários, as pessoas que residem em domicílios chefiados por mulheres apresentam melhores condições de bem-estar do que as que vivem nos chefiados por homens. Porém, o indicador aponta que este bem-estar é inferior ao alcançado pelas pessoas que vivem em domicílios chefiados por não beneficiários, sejam mulheres ou homens

Palavras-chave: Bem-estar. Vulnerabilidade Monetária. Bolsa-Família. Mulheres. Indicador.

\section{MULTIDIMENSIONAL WELL-BEING: A COMPARISON BETWEEN BENEFICIARY GROUPS OF FAMILIES FACING POVERTY AND VULNERABILITY}

Abstract: The purpose of this article is to compare the personal well-being of beneficiaries and nonbeneficiaries of CCT, living in two-parent and single parent households headed by men or by women. Departing from the HDI methodology, we build a Multidimensional Welfare Indicator (MWI) using microdata from the 2010 Census. The results show that people living in household headed by beneficiary women have better welfare conditions than those headed by beneficiary men. However, it is lower than the well-being conditions of people living in household headed by women and men who are not beneficiaries

Keywords: Well-being. Income Vulnerability. Bolsa-Família. Women. Indicator.

\section{MULTIDIMENSIONAL BIENESTAR: UNA COMPARACIÓN ENTRE GRUPOS DE FAMILIAS QUE VIEM EM POBREZA E VULNERABILIDAD}

Resumen: El objetivo de este artículo es comparar el bienestar de las personas beneficiarias y no beneficiarias del Programa Bolsa Família (PBF) que viven en domicilios bi y monoparentales dirigidos por hombres o mujeres que viven o no con un compañero. Fueron utilizados los micro datos del Censo de 2010 para construir un Indicador Multidimensional del bienestar (IMBE) inspirado en la metodología del desarrollo humano. Los resultados indican que las personas viviendo em hogares dirigidos por mujeres beneficiarias presentan mejores condiciones de bienestar de que aquellas viviendo em hogares encabezados por hombres beneficiarios. Sin

\footnotetext{
${ }^{1}$ Pontifícia Universidade Católica do Rio Grande do Sul, Escola de Negócios, Porto Alegre, Brasil, izete.bagolin@pucrs.br, http://orcid.org/0000-0003-4325-7677

2 Pontifícia Universidade Católica do Rio Grande do Sul, Escola de Negócios, Porto Alegre, Brasil, natalia.lindemayer@gmail.com, https://orcid.org/0000-0002-8169-802X

${ }^{3}$ Pontifícia Universidade Católica do Rio Grande do Sul, Escola de Negócios, Porto Alegre, Brasil, luana.fraga92@gmail.com, https://orcid.org/0000-0002-5115-6502
} 
embargo, este bienestar es inferior aquellas viviendo en hogares encabezados por mujeres y hombres no beneficiarios.

Palabras clave: Bienestar. Vulnerabilidad. Bolsa Família. Mujeres. Indicador.

\section{Introdução}

No período 2004-2009, a parcela de indivíduos extremamente pobres, pobres e vulneráveis, monetariamente, decresceu em tamanho absoluto, sendo que milhões de brasileiros escaparam da pobreza e da alta vulnerabilidade (OSORIO; SOUZA; SOARES; OLIVEIRA, 2011). Esse fato se torna positivo e relevante porque indivíduos em situação de privação financeira, além de possuírem um baixo nível de renda, tendem a apresentar escolaridade e qualificação profissional baixas, assim como limitado acesso a informações e a serviços básicos como saneamento e saúde. A soma desse conjunto de fatores, que se inter-relacionam, reforça a desigualdade existente na sociedade (SILVA, 2007).

Dentre as explicações para a redução da pobreza e da vulnerabilidade brasileira está o aumento real da renda domiciliar per capita, que ocorreu por meio de ajustes no salário mínimo e da expansão das transferências de renda do governo. O mais significante deles, o Programa Bolsa Família (PBF), ganhou importância para a composição da receita dos pobres, tornando-se uma complementação para a ascensão das famílias ao estrato vulnerável, parcela em que se encontra a maior parte das famílias beneficiárias (OSORIO; SOUZA; SOARES; OLIVEIRA, 2011). Ademais, o PBF ainda permite o empoderamento e a afirmação como cidadãs para as mulheres beneficiárias. De acordo com dados disponibilizados pelo governo federal, as mulheres têm prioridade para a titularidade do cartão Bolsa Família, pois tendem a usar o recurso para o bem-estar de toda a família (BRASIL, 2015; LAVINAS, COBO; VEIGA, 2012).

No entanto, apesar de o PBF contribuir para a distribuição de renda, reduzir o nível de pobreza e colaborar com a autonomia das mulheres, problemas que vão além da questão monetária ainda persistem. Uma maneira de abranger alguns desses problemas é considerando a pobreza não apenas em função da renda, mas, sim, encarando-a de forma multidimensional. A relevância de olhar para fenômenos sociais numa perspectiva multidimensional remonta-se a Kolm (1977) e Sen (1976; 1985; 1992), que, conceitualmente, atingiram considerável aceitação. Contudo, a identificação dos pobres, a mensuração da incidência e intensidade, bem como a 
elaboração de políticas de enfrentamento, ainda permanecem baseadas na visão e nas medidas unidimensionais e monetárias.

$\mathrm{Na}$ análise dos avanços alcançados, persistem fortes divergências e a necessidade de aprimoramento das medidas e políticas de enfrentamento da pobreza. Nessa perspectiva, a contribuição de Sen (1976) merece destaque por ter explicitado a necessidade de avançar nas metodologias de identificação dos pobres, ressaltando a importância de integrar outras características (dimensões) da pobreza. A partir dessa contribuição, diversos trabalhos foram desenvolvidos propondo e avaliando de forma multidimensional a pobreza.

É relevante destacar que, apesar da evolução nas formas de mensuração da pobreza e da identificação de benefícios trazidos pelo PBF, ainda persistem questões acerca da realidade das famílias que vivem em situação de pobreza e vulnerabilidade a serem investigadas, tais como: quais as características e os diferenciais nas condições de vida das pessoas que vivem em domicílios considerados em situação de pobreza ou vulnerabilidade? O bem-estar é significativamente superior nos domicílios chefiados por mulheres? Há diferenças no bem-estar entre domicílios beneficiários e não beneficiários do PBF, monoparentais e biparentais?

Com vistas a contribuir com esse debate, o presente artigo tem como objetivo geral construir um Indicador Multidimensional de Bem-Estar (IMBE) e, por meio deste, comparar o bem-estar dos domicílios chefiados por mulheres beneficiárias do PBF com o bem-estar de domicílios chefiados por mulheres não beneficiárias, assim como por homens beneficiários e não beneficiários, considerando também se os domicílios são monoparentais ou biparentais. Como objetivo específico, pretende-se calcular o IMBE para as regiões brasileiras.

Este estudo visa contribuir com a construção do indicador e o uso deste para a comparação de diferentes grupos de domicílios. Segundo Januzzi (2005, p. 138), os indicadores sociais "são medidas usadas para permitir a operacionalização de um conceito abstrato ou de uma demanda de interesse programático". Dessa forma, torna-se possível a identificação das dimensões do bem-estar que necessitam de maior intervenção governamental, no sentido de promover políticas públicas mais adequadas e direcionadas. Como justificativa, observa-se que, não obstante a pobreza ser definida, para fins de construção de indicadores, como insuficiência de renda, os indivíduos em situação de vulnerabilidade social sofrem privações em várias outras dimensões. Não se nega o fato de a renda ser uma boa proxy para o 
bem-estar, contudo, utilizá-la isoladamente não torna possível a identificação da composição e intensidade das outras privações vivenciadas pelos indivíduos (OSORIO; SOUZA; SOARES; OLIVEIRA, 2011).

O aprofundamento da compreensão sobre a realidade socioeconômica da população brasileira mais pobre explicita a existência de questões raciais, de gênero, relacionadas à escolaridade e ao acesso a serviços de infraestrutura domiciliar a serem trabalhadas por meio da implementação de ações intersetoriais em todas as esferas federativas (CAMARGO; CURRALERO; LICIO; MOSTAFA, 2013). Diante dessas constatações, pesquisar o bem-estar da parcela da população mais vulnerável, com base em um indicador multidimensional que englobe a maior parte dessas questões, torna-se relevante.

Para melhor apresentar a pesquisa realizada, o presente artigo está organizado em seções: após esta introdução, apresentam-se o referencial teórico-empírico; a base de dados, a seleção da amostra e das variáveis que compõem o indicador e a metodologia de construção do índice de bem-estar; a apresentação e discussão dos resultados e, por fim, são feitas as considerações finais.

\section{Referencial teórico-empírico}

\section{Programas de transferência de renda na América Latina}

O uso de transferência direta de renda para enfrentamento da pobreza tem sido uma estratégia recorrente e vem se alastrando entre os países da América Latina. Programas governamentais são criados com a finalidade de fornecer assistência para as famílias com carência de recursos e assim atenuar a pobreza corrente. Ao mesmo tempo, eles têm como objetivo estimular e aumentar o nível educacional de crianças e jovens, uma vez que são impostas condições para 0 recebimento do benefício (RESENDE; OLIVEIRA, 2008).

Tais programas de assistência aos indivíduos de baixa renda também ocorreram em outros países. O México, por exemplo, iniciou esse processo em 1997, quando implantou o programa Progresa, que tinha como objetivo principal apoiar as famílias em situação de pobreza extrema (CORBO; PASE, 2015). Na sequência, em 2000, a Colômbia implantou o programa Más Familias en acción (MEDELLÍN; PRADA, 2015) com a finalidade de aumentar a frequência de estudantes nos ensinos fundamental e médio, dar apoio monetário às famílias com 
crianças menores de 7 anos de idade e melhorar os cuidados na saúde dessas crianças e nas práticas de cuidados infantis, estimulando a prevenção contra a violência intrafamiliar.

No Chile, desde 2002, a pobreza passou a ser enfrentada pelo programa Chile Solidário, que busca dar proteção social integral às famílias em situação de vulnerabilidade e integrá-las aos programas sociais (CHILE, 2015; RACZYNSKI, 2008). Em 2005, o Uruguai instituiu o Plano de Atenção à Emergência Social (PANES), o qual deu início à implementação de políticas de transferência de renda condicionada no Uruguai. O objetivo do plano era reduzir os níveis de pobreza e aumentar a inclusão social por meio de transferências monetárias (CORBO; PASE, 2015).

A Bolívia deu seguimento ao uso dessa estratégia e, em 2006, iniciou o programa Bono Juancito Pinto (BJP), que buscava melhorar o acesso à educação e diminuir a pobreza para as futuras gerações via garantia de material escolar, transporte e alimentação para crianças e adolescentes (YAÑEZ; ROJAS; SILVA, 2011). Na Argentina, a principal política de transferência monetária condicionada foi criada em 2009 e denomina-se programa Asignación por Hijo para Protección Social $(\mathrm{AUH})$. Os objetivos desse programa consistem em trazer uma melhora nos indicadores relacionados às principais dimensões do bem-estar da população, como: pobreza, desigualdade, falta de moradia e vulnerabilidade (NACIONES UNIDAS, 2018).

Em âmbito brasileiro, o precursor desses programas foi o Bolsa Escola, o qual atendia às famílias pobres e com crianças em idade escolar. O recebimento desse auxílio era condicionado à realização de matrícula de todas as crianças em idade escolar da família e à frequência mínima de $85 \%$ nas aulas. O Bolsa Escola perdurou até 2003, momento em que o governo federal optou por unificar diferentes programas sociais de auxílio aos indivíduos de baixa renda, implementando assim o Programa Bolsa Família, a partir da Lei n. 10.836, de 9 de janeiro de 2004.

O PBF unificou o Programa Nacional de Renda Mínima vinculado à Educação (Bolsa Escola), o Programa Nacional de Renda Mínima vinculado à Saúde (Bolsa Alimentação), o Cadastramento Único do Governo Federal (CadÚnico), o Programa Auxílio-Gás e o Programa Nacional de Acesso à Alimentação (PNAA). A criação do PBF teve o intuito central de combater a fome e a miséria e promover a emancipação das famílias mais pobres do país, bem como dar acesso a serviços públicos básicos (SANTANA, 2007). Como forma de alcançar tais objetivos, 
condicionalidades referentes à frequência escolar, ao calendário vacinal, ao peso e à altura (para crianças de até 6 anos) e ao acompanhamento de gestantes durante 0 pré-natal foram exigidas para a manutenção do recebimento da transferência de renda (BRASIL, 2019).

O PBF foi criado em outubro de 2003 e possui três eixos principais: complemento de renda, acesso a direitos e articulação com outras ações. Todos os meses, as famílias atendidas pelo programa recebem um benefício em dinheiro, que é transferido diretamente pelo governo federal (BRASIL, 2015).

De acordo com Queiroz e Ckagnazaroff (2010), os programas sociais de transferência de renda, como o PBF e os outros citados, exercem papel importante na promoção da qualidade de vida e bem-estar da população pobre, pois o benefício proporciona acesso a recursos que antes esta não tinha. Conforme o estudo desenvolvido pelos autores, os beneficiários do PBF apresentaram melhora no bemestar devido às orientações e ao atendimento psicológico, além de o benefício promover condições de vida melhores às famílias por meio da renda extra e das condicionalidades, que promovem o acesso à educação e saúde.

Ademais, Lavinas, Cobo e Veiga (2012) afirmam que no âmbito das relações de gênero, a identificação das mulheres como as beneficiárias nominais da transferência promove um uso mais eficiente e efetivo de um recurso, evitando desperdícios e usos indevidos. Autonomia e poder, para as mulheres, significam ter mais liberdade e independência, principalmente do marido. Percebe-se assim que o PBF trouxe efeitos favoráveis nas relações de poder das mulheres, pois as colocou em situação de vantagem em relação aos outros membros familiares, fazendo com que estes passassem a respeitá-las mais (FIALHO, 2007).

Ressalta-se que, apesar da importância e dos benefícios gerados pelos programas de transferência de renda, há diversas críticas em relação a eles. De acordo com Neder, Alves Filho e Souza (2015), o PBF contribui para diminuir a fome no país, mas, por outro lado, acaba não afetando todo o conjunto da população que passa pela privação alimentar; além disso, é incapaz de aumentar o poder aquisitivo de forma expressiva, quando comparados os valores transferidos pelo programa ao preço da cesta básica.

Em relação ao trabalho, Rego e Pinzani (2014) argumentam que boa parte dos beneficiários vive em áreas rurais bastante isoladas e sem infraestrutura capaz de atrair investimentos privados, o que acaba dificultando a criação de empregos e a consequente renda advinda do trabalho. Outra questão debatida se refere à forma 
de identificação e enfrentamento da pobreza com o uso do conceito de pobreza unidimensional e monetária, mesmo que a literatura evidencie que a pobreza deve ser vista como um fenômeno multidimensional.

\section{Pobreza multidimensional}

Argumentos em favor da definição da pobreza como um fenômeno multidimensional vêm evoluindo e ganhando importância desde os trabalhos de Kolm (1977) e Sen $(1976 ; 1985 ; 1992)$ e pode-se assumir que, no que tange à questão conceitual, existe consenso sobre a sua multidimensionalidade. No entanto, esses avanços conceituais ainda não foram amplamente adotados nos processos de identificação dos pobres, mensuração da incidência e intensidade, bem como na elaboração de políticas de enfrentamento. As ações práticas ainda estão centradas, predominantemente, no uso de linhas de pobreza monetária. A contribuição de Sen (1976) merece destaque por ter explicitado a necessidade de avançar nas metodologias de identificação dos pobres, ressaltando a importância de integrar outras características (dimensões) da pobreza. De acordo com Codes (2008), a pobreza é vista como um fenômeno social complexo, no qual as privações sofridas pelos indivíduos não são apenas materiais, e sim relacionadas a levar uma vida compatível com o necessário para se atingir padrões de consumo que proporcionem a aceitação social e o autorrespeito. As carências e penúrias sofridas pela população pobre são múltiplas e relacionadas a padrões de vida de baixa expectativa, elevada morbidade e propensa a riscos, envolvendo parâmetros como condições de saúde, educação, habitação, acesso a direitos econômicos e sociais e liberdades políticas.

Battiston et al. (2013) estudaram a pobreza multidimensional de Argentina, Brasil, Chile, El Salvador, México e Uruguai e identificaram que, em todos os países, a privação do acesso ao saneamento e a educação inadequada do chefe de família foram as dimensões que mais contribuíram para a pobreza multidimensional geral. Outro estudo que construiu um índice multidimensional de pobreza no Brasil foi o de Silva e Neder (2010), em que compararam a pobreza entre estados, de forma unidimensional e multidimensional, sendo que alguns estados melhoram de posição em relação à medida unidimensional no ranking da pobreza se usada a medida multidimensional.

Evidências encontradas na operacionalização do conceito de pobreza multidimensional mostram que o grau de pobreza das famílias nordestinas encontra- 
se acima de todas as demais regiões brasileiras, em particular do Sudeste. Itens como acesso ao trabalho, disponibilidade de recursos e condições habitacionais demonstraram-se os mais precários (BARROS; CARVALHO; FRANCO, 2006).

\section{Procedimentos metodológicos}

Origem dos dados e amostra de interesse

Para o desenvolvimento da pesquisa, foram utilizados os microdados de pessoas e domicílios do Censo Demográfico de 2010 do Instituto Brasileiro de Geografia e Estatística (IBGE) (BRASIL, 2010). Foram consideradas pobres aquelas pessoas que vivem em domicílios onde a renda domiciliar per capita é inferior a $R \$$ 134,00 (cento e trinta e quatro reais) e vulneráveis aquelas que vivem em domicílios com renda domiciliar per capita entre $R \$ 134,00$ e inferior a um salário mínimo (que era equivalente a quatrocentos e sessenta e cinco reais). Esses valores correspondiam, em 2009, aos valores das linhas de pobreza e de vulnerabilidade oficiais do governo (OSORIO; SOUZA; SOARES; OLIVEIRA, 2011). Após agrupar as bases de pessoas e domicílios, obteve-se a amostra de interesse formada por pessoas em situação de pobreza e vulnerabilidade. A amostra resultou em 12.443,004 pessoas, que estão distribuídas em 3.143,487 domicílios, dos quais $1.975,161$ (62.83\%) são chefiados por homens e 1.168,326 (37.17\%) são chefiados por mulheres.

O interesse do presente estudo é comparar o bem-estar dos beneficiários e não beneficiários do PBF que vivem em domicílios bi e monoparentais, chefiados por homens ou por mulheres.

\section{Dimensões e construção do Indicador Multidimensional de Bem-Estar}

O bem-estar pode ser abordado como sinônimo de condições de vida (BUSS, 2000), saúde (SCHMIDT; POWER; BULLINGER; NOSIKOV, 2005), estilo de vida (NAHAS, 2003) e felicidade (RENWICK; BROWN, 1996), e os indicadores variam da renda até a satisfação com determinados aspectos da vida. De acordo com Januzzi (2005, p. 138), "os indicadores apontam, indicam, aproximam, traduzem em termos operacionais as dimensões sociais de interesse definidas a partir de escolhas teóricas ou políticas realizadas anteriormente".

Os indicadores sociais podem ser classificados segundo algumas características, sendo que umas delas é a área temática da realidade social a que 
se referem, como os seguintes indicadores: saúde, educação, mercado de trabalho, demografia, habitação, gênero, entre outros. Também podem ser classificados como objetivos ou subjetivos. Os indicadores objetivos referem-se a ocorrências concretas, construídos a partir das estatísticas públicas disponíveis. Por outro lado, os subjetivos são construídos com base na avaliação dos indivíduos ou especialistas com relação a diferentes aspectos da realidade (JANUZZI, 2005).

Eles podem também ser denominados analíticos ou sintéticos. O que os diferencia é o compromisso com a expressão mais analítica ou de síntese do indicador. Medidas como Índice de Preços ao Consumidor ou Índice de Desenvolvimento Humano (IDH), por exemplo, procuram sintetizar várias dimensões empíricas da realidade econômica e/ou social em uma única medida, portanto são considerados sintéticos. Ao contemplarem no seu cômputo um conjunto mais amplo de medidas, tendem a refletir o comportamento "médio" ou situação "típica" de uma determinada localidade em termos do desenvolvimento humano, vulnerabilidade social ou outro conceito operacional que lhes deu origem (JANUZZI, 2005). Em função desses aspectos conceituais e da alta complexidade de mensuração, são necessárias delimitações para possibilitar a operacionalização do bem-estar em análises científicas (DANTAS; SAWADA; MALERBO, 2003).

Assim, o indicador proposto no presente artigo pode ser classificado como um indicador objetivo e sintético, que trata o bem-estar a partir de uma ótica formal, por meio de um indicador que considera qualidade da moradia, acesso a serviços básicos, posse de bens duráveis, acesso à informação, educação e condições de trabalho. Nessa perspectiva, reiterando a importância de se investigar outras dimensões do bem-estar além da renda, Buss (2007) afirma que aqueles que dispõem de pior situação financeira são os que possuem maiores dificuldades de acesso a serviços e políticas públicas, habitações adequadas, água potável, saneamento, alimentos, educação, transporte, lazer e emprego fixo e seguro. Assim, a identificação de vulnerabilidades em diversas dimensões das condições de vida tende a revelar diferentes desafios a serem enfrentados para a superação da pobreza.

Osorio, Souza, Soares e Oliveira (2011) argumentam que a moradia, as condições de ocupação e a qualidade da construção podem proporcionar bem-estar para a família, desde que apresentem uma série de características que a tornem adequadas segundo os padrões vigentes na sociedade. Segundo Cohen, Bodstein, Kligerman e Marcondes (2007), a habitação é o lócus de sociabilidade do indivíduo e 
de sua família, lugar da construção e da consolidação da vida e da saúde, por isso deve apresentar condições mínimas que contribuam para a saúde e o bem-estar de seus membros e para sua dignidade humana. Ela tem sido abordada sob dois enfoques prioritários: condições da moradia, que compreendem os materiais usados na sua construção e o acesso à eletricidade, e condições de saneamento, as quais envolvem, principalmente, os serviços de abastecimento e de tratamento de água, o esgotamento sanitário e a coleta de lixo, considerados serviços básicos para o bom funcionamento dos domicílios (BRASIL, 2007).

Estudos que tratam fenômenos sociais pela perspectiva multidimensional e utilizam as bases de dados secundários disponíveis nos seus respectivos contextos, em geral, enfrentam desafios na escolha das dimensões a serem investigadas. No entanto, mesmo que os indicadores não sejam exatamente os mesmos nas diferentes bases de dados, as dimensões moradia, acesso a serviços, posse de bens e educação estão presentes na maioria dos estudos empíricos. Exemplo disso são os trabalhos de Afzal, Rafique e Hameed (2015); Agbodji, Batana e Ouedraogo (2015); Alkire e Foster (2011); Alkire e Seth (2015); Ângulo, Díaz e Pardo (2016); Chzhen e Ferrone (2017); Ervin et al. (2018); Fahel, Teles e Caminhas (2016); Montoya e Teixeira, (2017); Salahuddin e Zaman, (2012); Serra (2017); Sial, Noreen e Awan (2015); Vijaya, Lahoti e Swaminathan (2014) e Wu e Di (2017).

Entretanto, em estudos multidimensionais para países em desenvolvimento, onde as privações são mais amplas, outras dimensões têm sido frequentemente incluídas. Esse é o caso da dimensão acesso à informação, que foi incluída nos estudos de Alkire e Seth (2015); Chzhen e Ferrone (2017); Ervin et al. (2018); Montoya e Teixeira (2017); Vijaya, Lahoti e Swaminathan (2014). Da mesma forma, a dimensão condição de trabalho tem sido considerada relevante e foi incluída nos estudos de Agbodji, Batana e Ouedraogo (2015); Ângulo, Díaz e Pardo (2016); Ervin et al. (2018); Salahuddin e Zaman (2012).

Seguindo essa linha, o indicador de bem-estar proposto no artigo é composto por 6 dimensões, cada uma agregando diferentes variáveis, totalizando 19 indicadores, conforme apresentado no Quadro 1, a seguir. As dimensões foram selecionadas com base na literatura empírica acima apresentada e na disponibilidade de dados no Censo de 2010. Salienta-se que a construção matemática do indicador foi inspirada na metodologia do Índice de Desenvolvimento Humano, o qual leva em consideração mais de uma dimensão para sua composição, sendo estas a renda, saúde e educação. Cada uma dessas dimensões é formada 
por um ou mais indicadores, e para o cálculo do índice final é feita a ponderação média das três dimensões, sendo que o resultado varia de zero a um, em que zero representa nenhum desenvolvimento humano e um, desenvolvimento humano máximo para as unidades de análise consideradas.

Quadro 1 - Dimensões, variáveis utilizadas e padronização dos indicadores de cada dimensão

\begin{tabular}{|c|c|c|}
\hline Dimensão & Indicadores & Tratamento/composição \\
\hline \multirow{4}{*}{$\begin{array}{l}1 . \\
\text { Qualidade } \\
\text { da } \\
\text { moradia }\end{array}$} & $\begin{array}{l}\text { Condição de } \\
\text { ocupação }\end{array}$ & $\begin{array}{l}\text { Próprio de algum morador }- \text { já pago }=1 \\
\text { Próprio de algum morador }- \text { ainda pagando }=0.67 \\
\text { Alugado e cedido por empregador }=0.33 \\
\text { Cedido de outra forma ou outra condição }=0\end{array}$ \\
\hline & $\begin{array}{l}\text { Material } \\
\text { predominante } \\
\text { nas paredes }\end{array}$ & $\begin{array}{l}\text { Alvenaria com revestimento }=1 \\
\text { Alvenaria sem revestimento e madeira apropriada para construção } \\
\text { (aparelhada) }=0.8 \\
\text { Taipa revestida }=0.6 \\
\text { Taipa não revestida }=0.4 \\
\text { Madeira aproveitada }=0.2 \\
\text { Palha }=0.1 \\
\text { Outro material }=0.1 \\
\text { Sem parede }=0\end{array}$ \\
\hline & $\begin{array}{l}\text { Densidade } \\
\text { dormitório }\end{array}$ & $\begin{array}{l}\text { Até duas pessoas }=1 \\
\text { Mais que duas pessoas }=0\end{array}$ \\
\hline & $\begin{array}{l}\text { Densidade } \\
\text { banheiro }\end{array}$ & $\begin{array}{l}\text { Um banheiro ou mais para cada duas pessoas }=1 \\
\text { Menos de um banheiro para cada duas pessoas }=0.5 \\
\text { Sem banheiro }=0\end{array}$ \\
\hline \multirow{4}{*}{$\begin{array}{l}\text { 2. Acesso } \\
\text { a serviços } \\
\text { básicos }\end{array}$} & $\begin{array}{l}\text { Esgotamento } \\
\text { sanitário }\end{array}$ & $\begin{array}{l}\text { Rede geral de esgoto ou pluvial e fossa séptica }=1 \\
\text { Fossa rudimentar }=0.5 \\
\text { Vala, rio, lago ou mar ou outro }=0\end{array}$ \\
\hline & $\begin{array}{l}\text { Abastecimento } \\
\text { de água }\end{array}$ & $\begin{array}{l}\text { Rede geral de distribuição }=1 \\
\text { Poço ou nascente na propriedade }=0.83 \\
\text { Carro-pipa }=0.67 \\
\text { Poço ou nascente fora da propriedade, poço ou nascente na aldeia e } \\
\text { poço ou nascente fora da aldeia }=0.5 \\
\text { Água da chuva armazenada em cisterna }=0.33 \\
\text { Água da chuva armazenada de outra forma }=0.17 \\
\text { Rios, açudes, lagos e igarapés e outra }=0\end{array}$ \\
\hline & Destino do lixo & $\begin{array}{l}\text { Coletado diretamente por serviço de limpeza e colocado em caçamba } \\
\text { de serviço de limpeza }=1 \\
\text { Queimado (na propriedade) e enterrado (na propriedade) }=0.5 \\
\text { Jogado em terreno baldio ou logradouro e jogado em rio, lago, mar ou } \\
\text { outro destino }=0\end{array}$ \\
\hline & Energia elétrica & $\begin{array}{l}\text { Sim, de companhia distribuidora }=1 \\
\text { Sim, de outras fontes }=0.5 \\
\text { Não existe energia elétrica }=0\end{array}$ \\
\hline $\begin{array}{l}\text { 3. Posse } \\
\text { de bens } \\
\text { duráveis }\end{array}$ & $\begin{array}{l}\text { Existência ou } \\
\text { não dos bens }\end{array}$ & $\begin{array}{l}\text { Rádio, televisão, máquina de lavar roupa, geladeira, telefone celular, } \\
\text { microcomputador, motocicleta ou automóvel = indicador padronizado } \\
\text { entre } 0 \text { e } 1 \text {, sendo um para os domicílios com todos os itens e zero } \\
\text { para domicílios sem nenhum dos itens }\end{array}$ \\
\hline \multirow{3}{*}{$\begin{array}{c}4 . \\
\text { Indicador } \\
\text { de acesso } \\
\text { à } \\
\text { informação }\end{array}$} & Rádio & $\begin{array}{l}\text { Possui }=1 \\
\text { Não possui }=0\end{array}$ \\
\hline & TV & $\begin{array}{l}\text { Possui }=1 \\
\text { Não possui }=0\end{array}$ \\
\hline & $\begin{array}{l}\text { Acesso à } \\
\text { Internet }\end{array}$ & $\begin{array}{l}\text { Possui }=1 \\
\text { Não possui }=0\end{array}$ \\
\hline \multirow[t]{2}{*}{$\begin{array}{l}5 . \\
\text { Educação }\end{array}$} & Alfabetização & $\begin{array}{l}\text { Sim }=1 \text { (para idade superior a } 5 \text { anos) } \\
\text { Não }=1 \text { (para idade inferior a } 6 \text { anos) } \\
\text { Não }=0 \text { (para idade superior a } 5 \text { anos) }\end{array}$ \\
\hline & Frequência à & Sim, pública ou privada = 1 (para idade até 18 anos) \\
\hline
\end{tabular}




\begin{tabular}{|c|c|c|}
\hline Dimensão & Indicadores & Tratamento/composição \\
\hline & $\begin{array}{l}\text { escola ou } \\
\text { creche }\end{array}$ & $\begin{array}{l}\text { Não, mas já frequentou }=1 \text { (para pessoas com mais de } 18 \text { anos) } \\
\text { Não }=0\end{array}$ \\
\hline & Anos de estudo & $\begin{array}{l}\text { Médio completo ou mais }=1 \\
\text { Fundamental completo }=0.5 \\
\text { Pessoas com mais de } 25 \text { anos sem instrução ou fundamental } \\
\text { incompleto }=0\end{array}$ \\
\hline \multirow{4}{*}{$\begin{array}{l}6 . \\
\text { Condição } \\
\text { de } \\
\text { trabalho }\end{array}$} & $\begin{array}{l}\text { Existência de } \\
\text { trabalho } \\
\text { remunerado }\end{array}$ & $\begin{array}{l}\text { Sim }=1 \text { para pessoas com mais de } 18 \text { anos e menos de } 65 \\
\text { Sim }=1 \text { para pessoas entre } 14 \text { e } 18 \text { anos desde que estejam } \\
\text { estudando } \\
\text { Não }=1 \text { para pessoas que estejam estudando } \\
\text { Não }=1 \text { para pessoas com menos de } 14 \text { e mais de } 65 \text { anos } \\
\text { Não }=0 \text { para pessoas com mais de } 18 \text { anos e menos de } 65\end{array}$ \\
\hline & $\begin{array}{l}\text { Condição de } \\
\text { trabalho }\end{array}$ & $\begin{array}{l}\text { Empregado formal e empregador }=1 \\
\text { Crianças e idosos }=1 \\
\text { Conta própria }=0.67 \\
\text { Empregado sem carteira }=0.33 \\
\text { Desempregado e não remunerado }=0\end{array}$ \\
\hline & $\begin{array}{l}\text { Retorno do } \\
\text { trabalho para } \\
\text { casa } \\
\text { diariamente }\end{array}$ & $\begin{array}{l}\text { Sim }=1 \\
\text { Não }=0\end{array}$ \\
\hline & $\begin{array}{c}\text { Tempo } \\
\text { deslocamento }\end{array}$ & $\begin{array}{l}\text { Até meia hora }=1 \\
\text { De meia hora até uma hora }=0,5 \\
\text { Mais de uma hora }=0\end{array}$ \\
\hline
\end{tabular}

Fonte: Elaborado pelas autoras (2020).

Após a normalização dos indicadores dentro do intervalo zero e um, em que zero reflete a pior condição e um a condição desejada, foram construídos os subíndices por dimensão. Para isso, foi utilizada média aritmética, com peso igual para cada variável. O índice final é a média aritmética das 6 dimensões consideradas, construído para o Brasil e, posteriormente, para as regiões de forma individual.

Por fim, com o intuito de verificar se existem diferenças estatisticamente significativas do IMBE entre os grupos estudados (domicílios monoparentais e biparentais, chefiados por homens e mulheres, beneficiários do PBF e não beneficiários do PBF) e regiões brasileiras, foram realizados testes de diferenças de média. Para isso, foi utilizado o teste ANOVA, o qual compara a média de uma variável em um grupo com a média da mesma variável em outros grupos. Para esse teste, tem-se como hipótese nula: "não existem diferenças significativas entre os dois grupos" (CORRAR; PAULO; DIAS FILHO, 2009). Adicionalmente, foi estimada uma regressão por mínimos quadrados ordinários, tendo o IMBE como variável dependente, a renda domiciliar per capita como variável de controle e dummies para os grupos de interesse estudados. 


\section{Resultados}

\section{Estatísticas descritivas}

Com base na amostra do Censo, percebe-se na Tabela 1, a seguir, que do total de pessoas que vivem em situação de pobreza ou vulnerabilidade monetária, as mulheres representam o maior percentual, exceto no grupo das pessoas que vivem em domicílios cujo chefe conta com a companhia de um cônjuge. Ao olhar para as características somente dos chefes de domicílio, percebe-se que 0 percentual de homens chefes de domicílios é mais elevado em todos os grupos, exceto naquele dos domicílios monoparentais.

Tabela 1 - Número de domicílios beneficiários e não beneficiários, bi e monoparentais chefiados por homens e mulheres

\begin{tabular}{c|c|c|c}
\hline & \multicolumn{3}{|c}{ Homens } \\
\hline & Não beneficiários PF & Beneficiários do PBF & Total \\
\hline Biparentais & $1.112,657$ & 652.344 & 210.160 \\
\hline Monoparentais & 179.343 & 30.817 & $\mathbf{1 . 9 7 5 . 1 6 1}$ \\
\hline Total & $\mathbf{1 . 2 9 2 , 0 0 0}$ & $\mathbf{6 8 3 . 1 6 1}$ & Mulheres \\
\hline & \multicolumn{3}{|c}{ Total } \\
\hline Biparentais & 307.514 & 203.315 & 610.829 \\
\hline Monoparentais & 439.234 & 218.263 & 657.497 \\
\hline Total & $\mathbf{7 4 6 . 7 4 8}$ & $\mathbf{4 2 1 . 5 7 8}$ & $\mathbf{1 . 1 6 8 . 3 2 6}$
\end{tabular}

Fonte: Elaborada pelas autoras (2020), com base em Brasil (2010).

Na Tabela 2, a seguir, são apresentadas as estatísticas descritivas de gênero da população estudada.

Tabela 2 - Estatística descritiva das características gerais da amostra, dos chefes de domicílio e das pessoas que vivem em domicílios chefiados por homens ou por mulheres que vivem com ou sem a companhia de um cônjuge

\begin{tabular}{|c|c|c|}
\hline \multicolumn{3}{|c|}{ Composição de gênero da amostra em estudo (percentuais) } \\
\hline & \multicolumn{2}{|c|}{ Gênero } \\
\hline & Homens & Mulheres \\
\hline Total & 49,42 & 50,58 \\
\hline Não beneficiários do PBF & 49,50 & 50,50 \\
\hline Beneficiários do PBF & 49,31 & 50,69 \\
\hline Chefe dom. vive com cônjuge & 51,33 & 48,67 \\
\hline Chefe dom. não vive com cônjuge & 42,96 & 57,04 \\
\hline \multicolumn{3}{|c|}{ Composição e gênero dos chefes de domicílio } \\
\hline & \multicolumn{2}{|c|}{ Gênero } \\
\hline & Homens & Mulheres \\
\hline Total & 62,83 & 37,17 \\
\hline Não beneficiários do PBF & 63,37 & 36,63 \\
\hline Beneficiários do PBF & 61,84 & 38,16 \\
\hline Vivem com cônjuge & 77,55 & 22,45 \\
\hline Não vive com cônjuge & 24,22 & 75,78 \\
\hline \multicolumn{3}{|c|}{ Composição de gênero das pessoas que vivem em domicílios chefiados por homen } \\
\hline & \multicolumn{2}{|c|}{ Gênero } \\
\hline & Homens & Mulheres \\
\hline Total & 52,71 & 47,29 \\
\hline Não beneficiários do PBF & 53,30 & 46,70 \\
\hline
\end{tabular}




\begin{tabular}{c|c|c}
\hline Beneficiários do PBF & 51,85 & 48,15 \\
\hline Chefe dom. vive com cônjuge & 51,39 & 48,61 \\
\hline Chefe dom. não vive com cônjuge & 71,00 & 29,00 \\
\hline \multicolumn{2}{|c}{ Gomposição de gênero das pessoas que vivem em domicílios chefiados por mulheres } \\
\hline \multicolumn{2}{|c}{ Gênero } \\
\hline Total & Homens & Mulheres \\
\hline Não beneficiários do PBF & $\mathbf{4 3 , 6 8}$ & 57,32 \\
\hline Beneficiários do PBF & 42,71 & 55,00 \\
\hline Chefe dom. vive com cônjuge & 45,00 & 48,90 \\
\hline Chefe dom. não vive com cônjuge & 51,10 & 63,49 \\
\hline
\end{tabular}

Fonte: Elaborada pelas autoras (2020), com base em Brasil (2010).

No conjunto de pessoas que vivem em domicílios chefiados por mulheres, o percentual de mulheres é superior ao de homens na maioria dos subgrupos.

Indicador de bem-estar e subdimensões

Nesta seção, são apresentados e discutidos os resultados do IMBE para a população vulnerável e pobre do Brasil. Na Tabela 3, a seguir, é possível perceber que, para a totalidade da amostra, o valor do IMBE, numa escala de 0 a 1, é de 0,61, mas quando analisado pelos grupos estudados, verifica-se que o nível de bem-estar médio varia entre 0,57 e 0,64 .

Quando se separa a população vulnerável e pobre em beneficiária e não beneficiária do PBF, os valores do IMBE variam consideravelmente. O grupo de pessoas que vivem em domicílios que não possuem pessoas que recebem 0 benefício do PBF apresenta condições de bem-estar melhores do que aquelas com a presença de beneficiários. Evidencia-se também que os domicílios chefiados por mulheres, sejam estes monoparentais ou biparentais, apresentam bem-estar superior aos domicílios chefiados por homens, exceto entre os grupos de domicílios biparentais não beneficiários do PBF, em que o indicador de bem-estar é 0,64 tanto para os domicílios chefiados por mulheres quanto por homens. Os grupos dos chefes de domicílios homens beneficiários do Bolsa Família de domicílios monoparentais e biparentais são os que apresentam o IMBE mais baixo (ambos $0,57)$.

Esses resultados permitem perceber que, apesar de o benefício recebido permitir que a população deixe o grupo das pessoas pobres e ingresse no grupo dos vulneráveis, as diferenças em termos de privações ainda são evidentes. Além disso, os resultados encontrados no presente estudo estão alinhados com achados de 
Lavinas, Cobo e Veiga (2012) e Antunes e Romano (2002), no que se refere à melhor gestão dos recursos por parte das mulheres, evidenciando que quando se compara o bem-estar dos domicílios chefiados por homens e mulheres, aqueles chefiados por mulheres apresentam melhores indicadores médios de bem-estar. 
BAGOLIN, LINDEMAYER, FRAGA

Tabela 3 - IMBE e dimensões para pessoas que vivem em domicílios com características

específicas

\begin{tabular}{|c|c|c|c|c|c|c|c|c|}
\hline $\begin{array}{c}\text { Sexo chefe } \\
\text { domicílio }\end{array}$ & Características do domicílio & IMBE & $\begin{array}{c}\text { Qualidade } \\
\text { da casa }\end{array}$ & $\begin{array}{l}\text { Acesso a } \\
\text { serviços }\end{array}$ & $\begin{array}{c}\text { Posse de } \\
\text { bens }\end{array}$ & $\begin{array}{c}\text { Acesso à } \\
\text { Informação }\end{array}$ & Educação & $\begin{array}{c}\text { Condição no } \\
\text { trabalho }\end{array}$ \\
\hline \multirow{7}{*}{$\begin{array}{l}\text { Chefes de } \\
\text { ambos os } \\
\text { sexos }\end{array}$} & Amostra total & 0,61 & 0,71 & 0,82 & 0,54 & 0,59 & 0,54 & 0,46 \\
\hline & Não beneficiários do PBF & 0,64 & 0,73 & 0,86 & 0,58 & 0,62 & 0,56 & 0,47 \\
\hline & Beneficiários do PBF & 0,57 & 0,68 & 0,77 & 0,48 & 0,55 & 0,52 & 0,44 \\
\hline & Biparentais não beneficiários do PBF & 0,64 & 0,72 & 0,85 & 0,60 & 0,63 & 0,56 & 0,47 \\
\hline & Biparentais beneficiários do PBF & 0,57 & 0,68 & 0,75 & 0,49 & 0,56 & 0,52 & 0,44 \\
\hline & Monoparentais não beneficiários do PBF & 0,63 & 0,76 & 0,87 & 0,53 & 0,60 & 0,55 & 0,46 \\
\hline & Monoparentais beneficiários do PBF & 0,59 & 0,71 & 0,82 & 0,47 & 0,55 & 0,52 & 0,44 \\
\hline \multirow{4}{*}{ Homens } & Biparentais não beneficiários do PBF & 0,64 & 0,72 & 0,85 & 0,60 & 0,63 & 0,56 & 0,47 \\
\hline & Biparentais beneficiários do PBF & 0,57 & 0,67 & 0,74 & 0,49 & 0,56 & 0,52 & 0,44 \\
\hline & Monoparentais não beneficiários do PBF & 0,60 & 0,75 & 0,81 & 0,48 & 0,55 & 0,53 & 0,46 \\
\hline & Monoparentais beneficiários do PBF & 0,57 & 0,69 & 0,77 & 0,46 & 0,54 & 0,51 & 0,45 \\
\hline \multirow{4}{*}{ Mulheres } & Biparentais não beneficiárias do PBF & 0,64 & 0,73 & 0,87 & 0,59 & 0,62 & 0,56 & 0,47 \\
\hline & Biparentais beneficiárias do PBF & 0,58 & 0,68 & 0,79 & 0,49 & 0,56 & 0,52 & 0,44 \\
\hline & Monoparentais não beneficiárias do PBF & 0,64 & 0,76 & 0,89 & 0,55 & 0,61 & 0,56 & 0,46 \\
\hline & Monoparentais beneficiárias do PBF & 0,59 & 0,71 & 0,83 & 0,47 & 0,55 & 0,52 & 0,43 \\
\hline
\end{tabular}

Fonte: Elaborada pelas autoras (2020), com base em Brasil (2010) 
Cabe ainda olhar para esses diferenciais segundo as dimensões que compõem o IMBE entre os grupos estudados. Ao serem comparados os indicadores de cada dimensão entre os grupos de beneficiários e não beneficiários do PBF, é possível perceber que as dimensões que apresentam maior diferença entre os grupos são posse de bens (que inclui rádio, televisão, máquina de lavar roupa, geladeira, telefone celular, microcomputador, motocicleta e automóvel) e acesso a serviços (que engloba aspectos relacionados a esgotamento sanitário, abastecimento de água, destino do lixo e energia elétrica). Por outro lado, as dimensões condição no trabalho e educação apresentam as menores diferenças entre beneficiários e não beneficiários.

Infere-se que as maiores diferenças serem nas dimensões posse de bens e acesso a serviços ocorre em função de que beneficiários do PBF apresentam maior propensão a possuir menos recursos que aqueles que não são beneficiários, o que os impede de morar em locais com melhores condições sanitárias e possuir bens que em muitos casos custam valores exorbitantes, comparados a renda que possuem. Além disso, segundo o estudo de Neder, Alves Filho e Souza (2015) o valor mensal recebido do governo não é suficiente para comprar uma cesta básica adequada para alimentar toda uma família, supondo que ela seja composta de quatro pessoas. Dessa forma, se os recursos não são suficientes para alimentação, possuir bens como máquina de lavar, microcomputador e motocicleta por exemplo, torna-se inviável a essas famílias. Por outro lado, as dimensões referentes a educação e condições no trabalho, são aquelas que não dependem da renda das famílias, mas sim da iniciativa púbica, no caso das escolas e de oportunidades de trabalho. Assim, a diferença entre os grupos de beneficiários e não beneficiários tende a ser menor.

Considerando o sexo do chefe do domicílio e se o mesmo é monoparental ou biparental, encontrou-se que, em relação à dimensão qualidade da casa, os domicílios monoparentais chefiados por mulheres, apresentam menor privação. Tratando-se da dimensão acesso a serviços, nos domicílios biparentais chefiados por homens, o bem-estar é maior. Por outro lado, entre os domicílios chefiados por mulheres, o indicador de bem-estar nessa dimensão é maior entre os domicílios monoparentais.

Analisando-se a dimensão posse de bens e acesso à informação, tanto nos domicílios chefiados por homens como por mulheres, o resultado é melhor entre os domicílios biparentais. Na dimensão educação, os domicílios biparentais chefiados 
por homens apresentam menor privação. Por fim, na dimensão condição no trabalho, os domicílios biparentais que são chefiados por homens apresentam maior bem-estar e entre aqueles chefiados por mulheres, o IMBE é maior nos domicílios biparentais.

É possível identificar que os domicílios chefiados por homens que apresentam maior bem-estar são aqueles biparentais, ou seja, que tem a presença da mulher também. Por outro lado, os domicílios chefiados por mulheres que apresentam maior bem-estar são monoparentais, exceto na dimensão condição no trabalho. Isso evidencia a contribuição da presença da mulher para o bem-estar da família, independente da dimensão analisada. Ademais, tem-se o fato de que quando observados os aspectos relacionados ao trabalho, a mulher chefe de domicílio monoparental apresenta menor bem-estar, em muitos casos porque necessita abdicar do trabalho para estar com os filhos.

Com o intuito de verificar se os resultados apresentados na Tabela 3 são estatisticamente diferentes, foi realizado o teste de análise de variâncias ANOVA. Observa-se que quando o sig. é menor que 0,05, rejeita-se a hipótese nula de que não existem diferenças significativas entre as médias observadas. No presente caso, o sig. apresentou valor 0,000, indicando que há diferença de média significativa entre os grupos estudados. Diante desse resultado, realizou-se o teste Post Hoc Bonferroni. Os resultados estão apresentados na Tabela 4, a seguir. 
Tabela 4 - Resultados do Post Hoc Bonferroni após o teste de diferença de médias (ANOVA) do IMBE

\begin{tabular}{|c|c|c|c|c|c|c|c|c|c|}
\hline \multirow{3}{*}{\multicolumn{3}{|c|}{ Domicílios pobres e vulneráveis }} & \multicolumn{4}{|c|}{ Chefiados por homens } & \multicolumn{3}{|c|}{ Chefiados por mulheres } \\
\hline & & & \multicolumn{2}{|c|}{ Biparentais } & \multicolumn{2}{|c|}{ Monoparentais } & \multicolumn{2}{|c|}{ Biparentais } & \multirow{2}{*}{$\begin{array}{c}\text { Monoparentais } \\
\begin{array}{c}\text { Não benef. do } \\
\text { PBF }\end{array}\end{array}$} \\
\hline & & & $\begin{array}{c}\text { Não } \\
\text { benef. } \\
\text { do PBF }\end{array}$ & $\begin{array}{l}\text { Benef. } \\
\text { do PBF }\end{array}$ & $\begin{array}{c}\text { Não } \\
\text { benef. } \\
\text { do PBF }\end{array}$ & $\begin{array}{l}\text { Benef. } \\
\text { do PBF }\end{array}$ & $\begin{array}{c}\text { Não } \\
\text { benef. } \\
\text { do PBF }\end{array}$ & $\begin{array}{l}\text { Benef. } \\
\text { do PBF }\end{array}$ & \\
\hline \multirow{3}{*}{$\begin{array}{c}\text { Chefiados } \\
\text { por } \\
\text { homens }\end{array}$} & Biparentais & $\begin{array}{l}\text { Benef. do } \\
\text { PBF }\end{array}$ & $\begin{array}{c}- \\
0,067593 \\
(0,000)^{*}\end{array}$ & - & - & \multirow{3}{*}{-} & \multirow{4}{*}{-} & \multirow{5}{*}{-} & \multirow{6}{*}{-} \\
\hline & \multirow{2}{*}{ Monoparentais } & $\begin{array}{c}\text { Não } \\
\text { benef. do } \\
\text { PBF }\end{array}$ & $\begin{array}{c}- \\
0,042292 \\
(0,000)^{*}\end{array}$ & $\begin{array}{c}0,025301 \\
(0,000)^{*}\end{array}$ & & & & & \\
\hline & & $\begin{array}{c}\text { Benef. do } \\
\text { PBF }\end{array}$ & $\begin{array}{c}0,068485 \\
(0,000)^{*}\end{array}$ & $\begin{array}{c}-0,00089 \\
(0,407)\end{array}$ & $\begin{array}{c}0,026193 \\
(0,000)^{*}\end{array}$ & & & & \\
\hline \multirow{4}{*}{$\begin{array}{l}\text { Chefiados } \\
\text { por } \\
\text { mulheres }\end{array}$} & \multirow{2}{*}{ Biparentais } & $\begin{array}{c}\text { Não } \\
\text { benef. do } \\
\text { PBF }\end{array}$ & $\begin{array}{c}0,005111 \\
(0,000)^{*}\end{array}$ & $\begin{array}{c}0,072703 \\
(0,000)^{*}\end{array}$ & $\begin{array}{c}0,047402 \\
(0,000)^{*}\end{array}$ & $\begin{array}{c}0,073596 \\
(0,000)^{*}\end{array}$ & & & \\
\hline & & $\begin{array}{l}\text { Benef. do } \\
\text { PBF }\end{array}$ & $\begin{array}{c}- \\
0,058658 \\
(0,000)^{*}\end{array}$ & $\begin{array}{c}0,008934 \\
(0,000)^{*}\end{array}$ & $\begin{array}{c}- \\
0,016367 \\
(0,000)^{*}\end{array}$ & $\begin{array}{c}0,009826 \\
(0,000)^{*}\end{array}$ & $\begin{array}{c}- \\
0,063769 \\
(0,000)^{*}\end{array}$ & & \\
\hline & \multirow{2}{*}{ Monoparentais } & $\begin{array}{c}\text { Não } \\
\text { benef. do } \\
\text { PBF }\end{array}$ & $\begin{array}{c}0,000016 \\
(1,000)\end{array}$ & $\begin{array}{c}0,067576 \\
(0,000)^{*}\end{array}$ & $\begin{array}{c}0,042275 \\
(0,000)^{*}\end{array}$ & $\begin{array}{c}0,068468 \\
(0,000)\end{array}$ & $\begin{array}{c}0,005127 \\
(0,000)^{*}\end{array}$ & $\begin{array}{c}0,058642 \\
(0,000)^{*}\end{array}$ & \\
\hline & & $\begin{array}{c}\text { Benef. do } \\
\text { PBF }\end{array}$ & $\begin{array}{c}- \\
0,052068 \\
(0,000)^{*}\end{array}$ & $\begin{array}{c}0,015524 \\
(0,000)^{*}\end{array}$ & $\begin{array}{c}- \\
0,009777 \\
(0,000)^{*}\end{array}$ & $\begin{array}{c}0,016416 \\
(0,000)^{*}\end{array}$ & $\begin{array}{c}- \\
0,057179 \\
(0,000)^{*}\end{array}$ & $\begin{array}{l}0,00659 \\
(0,000)^{*} \\
\end{array}$ & $\begin{array}{c}-0,052052 \\
(0,000)^{*}\end{array}$ \\
\hline
\end{tabular}

Fonte: Elaborada pelas autoras (2020), com base em Brasil (2010).

Nota: *significativo ao nível de $1 \%$. 
Com esse teste foi possível verificar que existem diferenças de média significativas ao nível de $1 \%$ no IMBE entre os grupos estudados. As exceções foram os domicílios monoparentais e biparentais chefiados por homens beneficiários do PBF (sig. 0,407), entre o grupo de domicílios monoparentais chefiados por mulheres não beneficiárias do PBF e o grupo dos biparentais, chefiados por homens não beneficiários do PBF (sig.1,000).

Esses resultados revelam que existem diferenças estatisticamente significativas no nível de bem-estar quando analisada a amostra de acordo com o gênero do chefe do domicílio, se este é composto apenas pelo pai ou mãe ou pelos dois e se recebem ou não benefício do PBF. Evidencia-se que as maiores diferenças no nível de bem-estar são entre os domicílios biparentais chefiados por mulheres não beneficiárias do PBF e os monoparentais e biparentais chefiados por homens beneficiários do $\operatorname{PBF}(0,073596$ e 0,072703 , respectivamente). Do contrário, a menor diferença é entre os domicílios monoparentais chefiados por mulheres não beneficiárias do PBF e aqueles biparentais chefiados por homens não beneficiários do $\operatorname{PBF}(0,000016)$.

Tal resultado vai ao encontro do que foi evidenciado por Buss (2007), que mostrou que aqueles que dispõem de pior situação financeira, no caso os beneficiários do PBF, são também os que têm maiores dificuldades de acesso a serviços, habitações adequadas, água potável, saneamento, alimentos, educação, transporte, lazer, emprego fixo e seguro. Em relação à falta de acesso a alimentos, Neder, Alves Filho e Souza (2015) tinham observado que o benefício financeiro oferecido pelo PBF, apesar de aumentar o poder aquisitivo das famílias, não é comparável ao preço da cesta básica, o que acaba por não erradicar a fome.

Tratando da questão do emprego fixo, os resultados da presente pesquisa corroboram o que foi colocado por Rego e Pinzani (2014), isto é, que muitos beneficiários têm dificuldade em conseguir empregos fixos e com remuneração adequada, pois vivem em áreas rurais ou bastante isoladas. Salienta-se ainda que muitos dos beneficiários obtêm renda de trabalhos informais, não garantindo assim uma renda mensal que possa cobrir todas as necessidades de sua família. $\mathrm{Na}$ Tabela 5, a seguir, é possível visualizar os resultados do IMBE por regiões brasileiras. 
Tabela 5 - Indicador multidimensional de bem-estar das regiões brasileiras por grupos

\begin{tabular}{|c|c|c|c|c|c|c|}
\hline \multirow{2}{*}{$\begin{array}{l}\text { Sexo do } \\
\text { chefe do } \\
\text { domicílio }\end{array}$} & \multirow{2}{*}{ Características do domicílio } & \multicolumn{5}{|c|}{ IMBE por regiões brasileiras } \\
\hline & & Norte & Nordeste & Sudeste & Sul & Centro-Oeste \\
\hline \multirow{7}{*}{$\begin{array}{l}\text { Chefes } \\
\text { de ambos } \\
\text { os sexos }\end{array}$} & Amostra total & 0,54 & 0,58 & 0,66 & 0,66 & 0,62 \\
\hline & Não beneficiários do PBF & 0,56 & 0,60 & 0,68 & 0,67 & 0,64 \\
\hline & Beneficiários do PBF & 0,53 & 0,56 & 0,62 & 0,62 & 0,61 \\
\hline & $\begin{array}{l}\text { Biparentais não beneficiários do } \\
\text { PBF }\end{array}$ & 0,55 & 0,61 & 0,68 & 0,68 & 0,64 \\
\hline & Biparentais beneficiários do PBF & 0,52 & 0,56 & 0,62 & 0,62 & 0,61 \\
\hline & $\begin{array}{l}\text { Monoparentais não beneficiários } \\
\text { do PBF }\end{array}$ & 0,57 & 0,59 & 0,67 & 0,66 & 0,64 \\
\hline & $\begin{array}{l}\text { Monoparentais beneficiários do } \\
\text { PBF }\end{array}$ & 0,55 & 0,57 & 0,63 & 0,63 & 0,61 \\
\hline \multirow{4}{*}{ Homens } & $\begin{array}{l}\text { Biparentais não beneficiários do } \\
\text { PBF }\end{array}$ & 0,54 & 0,61 & 0,68 & 0,67 & 0,64 \\
\hline & Biparentais beneficiários do PBF & 0,51 & 0,56 & 0,62 & 0,62 & 0,60 \\
\hline & $\begin{array}{l}\text { Monoparentais não beneficiários } \\
\text { do PBF }\end{array}$ & 0,52 & 0,55 & 0,65 & 0,64 & 0,60 \\
\hline & $\begin{array}{l}\text { Monoparentais beneficiários do } \\
\text { PBF }\end{array}$ & 0,53 & 0,55 & 0,63 & 0,62 & 0,61 \\
\hline \multirow{4}{*}{ Mulheres } & $\begin{array}{l}\text { Biparentais não beneficiárias do } \\
\text { PBF }\end{array}$ & 0,58 & 0,61 & 0,68 & 0,68 & 0,64 \\
\hline & Biparentais beneficiárias do PBF & 0,55 & 0,56 & 0,63 & 0,63 & 0,61 \\
\hline & $\begin{array}{l}\text { Monoparentais não beneficiárias } \\
\text { do PBF }\end{array}$ & 0,59 & 0,61 & 0,67 & 0,67 & 0,65 \\
\hline & $\begin{array}{l}\text { Monoparentais beneficiárias do } \\
\text { PBF }\end{array}$ & 0,56 & 0,57 & 0,63 & 0,63 & 0,62 \\
\hline
\end{tabular}

Fonte: Elaborada pelas autoras (2020), com base em Brasil (2010).

Evidencia-se que as Regiões Sudeste e Sul apresentam os melhores indicadores de bem-estar, sendo que muitos deles são iguais ou com valores bem próximos. Por outro lado, as Regiões Norte e Nordeste apresentam os menores IMBE. Alguns resultados evidenciados por Sátyro (2014) acabam por justificar os achados da presente pesquisa, sendo que um deles é que a diminuição média do índice de pobreza entre os anos de 2003 e 2012 nos estados das Regiões Norte e Nordeste foi metade da ocorrida no restante do país. Foi observado também que os adolescentes estavam estudando mais e permanecendo um tempo maior na escola, entretanto os adolescentes nordestinos e nortistas apresentavam percentuais bem menores do que aqueles residentes nas Regiões Sul e Sudeste. Em relação ao trabalho, em 2012, todos os estados das Regiões Nordeste e Norte, com exceção de Rondônia, possuíam mais da metade de sua força de trabalho inserida precariamente no mercado de trabalho.

De forma geral, Nordeste e Norte tiveram níveis de acesso a serviços básicos muito mais baixos quando comparados aos estados das Regiões Sul e Sudeste. A discrepância entre os mundos de bem-estar evidencia os acessos diferenciados a serviços básicos necessários para a manutenção e qualidade de vida entre os 
indivíduos brasileiros (SÁTYRO, 2014).Os achados do presente estudo estão em consonância com os resultados de Fraga, Bender Filho, Coronel e Vieira (2017), que evidenciam que as Regiões Norte e Nordeste apresentam os piores cenários de pobreza. Um aspecto a ser destacado refere-se aos resultados para a Região Norte do país, pois além de ser a região com os piores resultados para todos os grupos estudados, é a única na qual os domicílios chefiados por homens não beneficiários apresentam resultados inferiores aos chefiados por mulheres beneficiárias, tanto para domicílios monoparentais como para biparentais. É possível explicar tal resultado porque as famílias beneficiárias do PBF necessitam atender às condicionalidades do programa, principalmente as relacionadas à educação. Assim, como o IMBE engloba frequência escolar de crianças e jovens, o fato de ser beneficiário pode contribuir para o bem-estar dessas famílias, comparadas às famílias de não beneficiários com rendas semelhantes.

Santos, Ceccato, Delatorre e Bonolo (2019) encontraram em sua revisão sistemática sobre os impactos do PBF em indicadores educacionais que alunos beneficiários do PBF tinham, em 2005, 34\% de chances a menos de abandonar a escola do que crianças de famílias com limite de renda domiciliar correspondente à elegibilidade do PBF, mas que não eram beneficiárias. Além disso, segundo o estudo de Cacciamali, Tatei e Batista (2010), o maior impacto do PBF na possibilidade de a criança só estudar ocorre na Região Norte, o que é de muita relevância, pois no momento que a criança tem a necessidade de trabalhar, ela tende a diminuir a frequência escolar. Ainda em relação ao Norte, destaca-se que ele apresentava o maior crescimento de famílias a serem atendidas pelo PBF $(23,2 \%)$, ou seja, famílias que viviam em situação de pobreza e extrema pobreza, mas que não tinham acesso ao PBF (BRASIL, 2012).

Identificou-se que há maior diferença entre a região que tem o maior e o menor IMBE, Sudeste e Norte, respectivamente, entre os domicílios biparentais chefiados por homens não beneficiários do PBF. Os domicílios monoparentais chefiados por mulheres apresentam IMBE maior que os chefiados por homens, exceto na Região Sudeste, onde o IMBE é igual entre os domicílios monoparentais chefiados por homens e mulheres. Infere-se que o fato de as famílias monoparentais chefiadas por mulheres apresentarem maior IMBE seja explicado por elas investirem a grande maioria do seu ganho na manutenção do domicílio, o que resulta em efeitos positivos para nutrição, saúde e educação dos membros da família. Além disso, os domicílios comandados por mulheres contam com maior acesso à 
participação em redes sociais de apoio familiar e a recursos externos, como a inclusão em programas sociais (MACEDO, 2008).

Em relação aos domicílios biparentais, nas Regiões Nordeste, Sudeste e Centro-Oeste, o IMBE é o mesmo entre o grupo dos chefiados por homens não beneficiários do PBF. Apenas na Região Nordeste os domicílios biparentais beneficiários do PBF apresentam o mesmo IMBE entre os chefiados por homens e mulheres. Destaca-se que, na Região Centro-Oeste, os domicílios monoparentais chefiados por homens beneficiários do PBF apresentam o IMBE maior que o dos domicílios não beneficiários. Já no Nordeste, o IMBE é o mesmo entre esses dois grupos de domicílios. No restante das regiões e dos grupos, o bem-estar dos domicílios não beneficiários é maior do que os beneficiários. As maiores diferenças entre os grupos de beneficiários e não beneficiários são entre os domicílios da região Sudeste, biparentais e chefiados por homens, seguidos dos domicílios das regiões Sul, Sudeste e Nordeste, biparentais e chefiados por mulheres, e dos domicílios biparentais chefiados por homens nas regiões Sul e Nordeste.

Com o intuito de verificar se as diferenças do IMBE são estatisticamente diferentes entre as regiões brasileiras, foi realizado o teste de diferença de média ANOVA, o qual apresentou sig. de 0,000. Assim, foi realizado o Post Hoc de Bonferroni, conforme apresentado na Tabela 6, a seguir.

Tabela 6 - Resultados do Post Hoc Bonferroni após o teste de diferença de médias (ANOVA) do IMBE para as regiões brasileiras

\begin{tabular}{|c|c|c|c|c|c|}
\hline Regiões & Norte & Nordeste & Sudeste & Sul & Centro-Oeste \\
\hline Norte & - & \multirow[b]{2}{*}{-} & \multirow{3}{*}{-} & \multirow{4}{*}{-} & \multirow{5}{*}{-} \\
\hline Nordeste & $\begin{array}{c}0,0355 \\
(0,000)^{*}\end{array}$ & & & & \\
\hline Sudeste & $\begin{array}{c}0,117892 \\
(0,000)^{*}\end{array}$ & $\begin{array}{c}0,082391 \\
(0,000)^{*}\end{array}$ & & & \\
\hline Sul & $\begin{array}{l}0,11379 \\
(0,000)^{*}\end{array}$ & $\begin{array}{l}0,07829 \\
(0,000)^{*}\end{array}$ & $\begin{array}{c}-0,004102 \\
(0,000)^{*}\end{array}$ & & \\
\hline Centro-Oeste & $\begin{array}{c}0,082112 \\
(0,000)^{*}\end{array}$ & $\begin{array}{c}0,046611 \\
(0,000)^{*}\end{array}$ & $\begin{array}{c}-0,03578 \\
(0,000)^{*}\end{array}$ & $\begin{array}{c}0,031678 \\
(0,000)^{*}\end{array}$ & \\
\hline
\end{tabular}

Fonte: Elaborada pelas autoras (2020), com base em Brasil (2010).

Nota: * significativo ao nível de $1 \%$.

Adicionalmente, buscando verificar a significância das diferenças encontradas no valor do IMBE entre beneficiários e não beneficiários, foram realizados os testes acima citados. Os resultados mostram-se significantes e estão apresentados na Tabela 7, na sequência. 
Tabela 7 - Resultados do Post Hoc Bonferron após o teste de diferença de médias (ANOVA) do IMBE para beneficiários e não beneficiários do PBF nas regiões brasileiras

\begin{tabular}{|c|c|c|c|c|c|}
\hline Regiões & $\begin{array}{l}\text { Não benef. } \\
\text { Norte }\end{array}$ & $\begin{array}{l}\text { Não benef. } \\
\text { Nordeste }\end{array}$ & $\begin{array}{l}\text { Não benef. } \\
\text { Sudeste }\end{array}$ & Não benef. Sul & $\begin{array}{l}\text { Não benef. } \\
\text { Centro-Oeste }\end{array}$ \\
\hline $\begin{array}{c}\text { Beneficiário } \\
\text { Norte }\end{array}$ & $\begin{array}{l}-.026747 \\
(0,000)^{*}\end{array}$ & - & \multirow[b]{2}{*}{-} & \multirow{3}{*}{-} & \multirow{4}{*}{-} \\
\hline $\begin{array}{c}\text { Beneficiário } \\
\text { Nordeste }\end{array}$ & \multirow{4}{*}{-} & $\begin{array}{c}-.041407 \\
(0,000)^{*}\end{array}$ & & & \\
\hline $\begin{array}{l}\text { Beneficiário } \\
\text { Sudeste }\end{array}$ & & \multirow{3}{*}{-} & $\begin{array}{c}-.052842 \\
(0,000)^{*}\end{array}$ & & \\
\hline $\begin{array}{c}\text { Beneficiário } \\
\text { Sul }\end{array}$ & & & \multirow[t]{2}{*}{ (1) } & $\begin{array}{c}-.050216 \\
(0,000)^{*}\end{array}$ & \\
\hline $\begin{array}{l}\text { Beneficiário } \\
\text { Centro-Oeste }\end{array}$ & & & & - & $\begin{array}{c}-.028849 \\
(0,000)^{*}\end{array}$ \\
\hline
\end{tabular}

Fonte: Elaborada pelas autoras (2020), com base em Brasil (2010).

Nota: * significativo ao nível de $1 \%$.

Foi possível verificar estatisticamente, por intermédio da ANOVA e do Post Hoc, que o IMBE varia entre as regiões ao nível de significância de 1\%. As maiores diferenças são entre Norte e Sudeste e Norte e Sul $(0,117892$ e 0,117892 respectivamente), e a menor diferença é entre Sul e Centro-Oeste $(0,031678)$. Esses resultados apenas confirmam que as diferenças entre as regiões, evidenciadas na Tabela 5, são estatisticamente significativas.

Buscando controlar o efeito da renda sobre o IMBE, foi estimado um modelo de mínimos quadrados ordinários, tendo o IMBE como variável dependente, e a renda domiciliar per capita e dummies para os grupos de interesse e regiões como variáveis explicativas. Os resultados são mostrados na Tabela 8, a seguir.

Tabela 8 - Efeito da renda e das diferentes composições de domicílios sobre o IMBE

\begin{tabular}{|c|c|c|}
\hline \multicolumn{2}{|l|}{ Variáveis explicativas } & IMBE \\
\hline Renda domiciliar per capita & v6531 & $\begin{array}{r}0.000320^{* * *} \\
(2.69 \mathrm{e}-07)\end{array}$ \\
\hline $\begin{array}{l}\text { Dummy para pessoas que vivem em domicílios biparentais } \\
\text { chefiados por homens beneficiários do PBF }\end{array}$ & hbb & $\begin{array}{l}-0.0241^{* * *} \\
(8.87 e-05)\end{array}$ \\
\hline $\begin{array}{l}\text { Dummy para pessoas que vivem em domicílios monoparentais } \\
\text { chefiados por homens não beneficiários do PBF }\end{array}$ & hmnb & $\begin{array}{l}-0.0267^{* * *} \\
(0.000185)\end{array}$ \\
\hline $\begin{array}{l}\text { Dummy para pessoas que vivem em domicílios monoparentais } \\
\text { chefiados por homens beneficiários do PBF }\end{array}$ & $\mathrm{hmb}$ & $\begin{array}{l}-0.0366^{* * *} \\
(0.000329)\end{array}$ \\
\hline $\begin{array}{l}\text { Dummy para pessoas que vivem em domicílios biparentais } \\
\text { chefiados por mulheres não beneficiárias do PBF }\end{array}$ & $\mathrm{mbnb}$ & $\begin{array}{l}0.00659^{\star * \star} \\
(0.000116)\end{array}$ \\
\hline $\begin{array}{l}\text { Dummy para pessoas que vivem em domicílios biparentais } \\
\text { chefiados por mulheres beneficiárias do PBF }\end{array}$ & $\mathrm{mbb}$ & $\begin{array}{l}-0.0155^{\star \star *} \\
(0.000128)\end{array}$ \\
\hline $\begin{array}{l}\text { Dummy para pessoas que vivem em domicílios monoparentais } \\
\text { chefiados por mulheres não beneficiárias do PBF }\end{array}$ & $\mathrm{mmnb}$ & $\begin{array}{l}0.00445^{* * *} \\
(0.000110)\end{array}$ \\
\hline $\begin{array}{l}\text { Dummy para pessoas que vivem em domicílios monoparentais } \\
\text { chefiados por mulheres beneficiárias do PBF }\end{array}$ & $\mathrm{mmb}$ & $\begin{array}{l}-0.0140^{* * *} \\
(0.000133)\end{array}$ \\
\hline Dummy para pessoas que vivem na região Nordeste & dnord & $\begin{array}{l}0.0384^{* * *} \\
(0.000111)\end{array}$ \\
\hline Dummy para pessoas que vivem na região Sudeste & dsudeste & $\begin{array}{c}0.0908^{* \star *} \\
(0.000116)\end{array}$ \\
\hline Dummy para pessoas que vivem na região Sul & dsul & $0.0830^{\star \star \star}$ \\
\hline
\end{tabular}




\begin{tabular}{l|c|c}
\hline & & $(0.000136)$ \\
\hline Dummy para pessoas que vivem na região Centro Oeste & dcoeste & $0.0577^{* * *}$ \\
& & $(0.000160)$ \\
\hline & Constante & $0.501^{* * *}$ \\
& & $(0.000123)$ \\
\cline { 2 - 3 } & Observações & $12,443,004$ \\
\hline
\end{tabular}

Standard errors in parentheses

${ }^{* * *} p<0.01,{ }^{* *} p<0.05,{ }^{*} p<0.1$

Nota 1. A categoria de referência para as dummies de grupos de domicílios é a dos domicílios biparentais chefiados por homens não beneficiários.

Nota 2. A categoria de referência para as dummies de região é Norte.

Os resultados mostram que, apesar de a renda apresentar coeficiente estatisticamente significativo, o seu valor é menor do que o coeficiente da maioria das dummies. Os coeficientes das dummies de grupos de domicílios comparam o bem-estar de cada um dos demais grupos em relação ao bem-estar das famílias que vivem em domicílios biparentais chefiados por homens não beneficiários do PBF. Os coeficientes das dummies de região comparam o bem-estar de cada região em relação a Região Norte, que foi utilizada como referência. Todos os coeficientes apresentaram diferença significativa em relação aos seus grupos de referência; a amplitude da amostra favorece esse resultado.

Percebe-se que somente as pessoas que vivem em domicílios chefiados por mulheres não beneficiárias do PBF (sejam eles mono ou biparentais) possuem bemestar maior do que aquelas que vivem nos domicílios de referência. Os demais arranjos familiares apresentam coeficiente negativo, isto é, índice de bem-estar inferior ao dos domicílios referenciais; sendo os piores resultados atribuídos às pessoas que vivem em domicílios monoparentais chefiados por homens beneficiários.

No contraste entre beneficiários e não beneficiários, quem vive em melhores condições, são as famílias do segundo grupo. Por um lado, há evidencia de que a renda complementar, distribuída pelo PBF, está sendo direcionada à população que sofre de mais privações; por outro revela-se que, mesmo aprimorando o bem-estar dos beneficiários, a concessão de renda não atinge algumas carências dessa população, como por exemplo o saneamento básico. Os coeficientes das dummies das regiões evidenciam que, em comparação à Região Norte as demais regiões apresentam bem-estar superior, com destaque para a Região Sudeste e Sul do país. 


\section{Considerações finais}

A operacionalização do conceito de bem-estar é uma tarefa complexa e que a literatura não apresenta uma solução única. Neste artigo, optou-se por avaliá-lo de forma objetiva, com a construção de um Indicador Multidimensional de Bem-Estar. Para isso, foram utilizadas as características dos indivíduos e domicílios que impactam diariamente na vida da população pobre. Mais especificamente, o objetivo foi avaliar o bem-estar das pessoas que vivem em domicílios em situação de vulnerabilidade e pobreza, pois estas sofrem privações importantes. Buscou-se ainda separar pelo gênero do chefe de domicílio, se os domicílios são mono ou biparentais e se são beneficiários ou não do Programa Bolsa Família.

Através da construção do indicador, verificou-se que as pessoas que dependem do PBF apresentam bem-estar significativamente inferior do que aquelas que não dependem. Quanto ao gênero do chefe de domicílio, as mulheres não beneficiárias do PBF foram as que apresentaram os melhores resultados no índice, e os homens beneficiários foram os que apresentaram os piores resultados. $O$ fato de o domicílio ser monoparental ou biparental não levou a uma diferença significativa no grupo dos domicílios chefiados por mulheres não beneficiárias e no de homens beneficiários. Entre os domicílios chefiados por homens não beneficiários do PBF, o IMBE é maior para os biparentais em comparação com os monoparentais e. entre aqueles chefiados por mulheres beneficiárias do PBF, os monoparentais apresentam um maior IMBE. Esse resultado sugere que a presença da mulher é positiva para o bem-estar das pessoas que vivem no domicílio, mesmo ela não sendo a chefe do domicílio.

Os diferenciais de bem-estar não se restringem ao fato de os chefes de domicílio serem beneficiários ou não beneficiários, de os domicílios serem chefiados por mulheres ou homens e mono ou biparentais. Uma vez que as regiões do país apresentam níveis de desenvolvimento distintos, os resultados em termos de bemestar multidimensional apresentam particularidades regionais importantes que merecem ser consideradas pelos formuladores de políticas públicas para que sua atuação seja mais eficaz. Com base nos resultados encontrados neste estudo, sugere-se uma maior atenção às regiões Norte e Nordeste, que apresentaram níveis de bem-estar inferiores aos de outras regiões.

Mais especificamente, visto que se mostrou relevante e merecedor de maior atenção, o indicador de posses de bens duráveis apresentou uma carência por parte dos domicílios estudados. Não possuir máquina de lavar, geladeira, televisão e 
microcomputador com Internet é algo que, sem dúvida, restringe a qualidade de vida dos indivíduos e os impossibilita de viver uma vida com o mínimo de bem-estar.

Salienta-se que, raramente, um programa social independente é capaz de melhorar o bem-estar de uma sociedade, dadas as suas múltiplas facetas. É necessário que se reconheça a complexidade das carências dos indivíduos em situação de vulnerabilidade e se tente amenizá-las, para que os domicílios tenham condições de encontrar soluções para quebrar o círculo vicioso da pobreza e assim atinjam o que considerem uma situação de bem-estar. Este estudo mostrou que os beneficiários do PBF apresentam menor bem-estar que os não beneficiários, porém, se não existisse tal política, a situação poderia ser ainda mais desvantajosa para os domicílios beneficiários.

Como limitações do estudo, cabe mencionar a não disponibilidade de dados referentes ao bem-estar subjetivo, como características psicológicas e espirituais dos indivíduos pesquisados no Censo de 2010, além da falta de dados mais recentes para tal investigação. Para pesquisas futuras, recomenda-se englobar características referentes à saúde e ao lazer, além de questões referentes ao bemestar subjetivo. Adicionalmente, pode ser realizada uma avaliação do quanto questões como a posse de bens duráveis e informação evoluíram ao longo da última década.

\section{REFERÊNCIAS}

AFZAL, Muhammad; RAFIQUE, Shamim; HAMEED, Farhan. Measurement of living standards deprivation in Punjab using AF method (periodical comparison approach). The Pakistan Development Review, v. 54, n. 4, p. 739-762, 2015.

AGBODJI, Akoété Ega; BATANA, Yélé Maweki; OUEDRAOGO, Dénis. Gender inequality in multidimensional welfare deprivation in West Africa: The case of Burkina Faso and Togo. International Journal of Social Economics, v. 42, n. 11, p. 980-1004, 2015.

ALKIRE, Sabina; FOSTER, James. Counting and multidimensional poverty measurement. Journal of Public Economics, v. 95, n. 7-8, p. 476-487, 2011.

ALKIRE, Sabina; SETH, Suman. Multidimensional poverty reduction in India between 1999 and 2006: Where and how? World Development, v. 72, p. 93-108, 2015.

ÂNGULO, Roberto; DÍAZ, Yadira; PARDO, Renata. The Colombian multidimensional poverty index: Measuring poverty in a public policy context. Social Indicators Research, v. 127, n. 1, p. 1-38, 2016.

ANTUNES, Marta; ROMANO, Jorge O. Empoderamento e direitos no combate à pobreza. Rio de Janeiro: ActionAid Brasil, 2002. 
BARROS, Ricardo Paes; CARVALHO, Mirela de; FRANCO, Samuel. Pobreza multidimensional no Brasil. In: INSTITUTO DE PESQUISA ECONÔMICA APLICADA (IPEA). Textos para discussão n. 1227. Brasília, DF: IPEA, 2006. Disponível em:

<http://www.ipea.gov.br/portal/images/stories/PDFs/TDs/td_1227.pdf>. Acesso em: 28 fev. 2020.

BATTISTON, Diego et al. Income and beyond: Multidimensional poverty in six Latin American countries. Social Indicators Research, v. 112, n. 2, p. 291-314, 2013.

BRASIL. Ministério da Cidadania. Secretaria Especial do Desenvolvimento Social, Bolsa Família, 2019. Disponível em: <http://www.desenvolvimentosocial.gov.br/servicos/bolsafamilia>. Acesso em: 28 fev. 2020.

BRASIL. Instituto Brasileiro de Geografia e Estatística (IBGE). Síntese de Indicadores Sociais. Uma análise das condições de vida da população brasileira 2007. Estudos \& Pesquisas, n. 21, 2007.

BRASIL. Ministério da Cidadania. O que é, 2015. Disponível em: <http://mds.gov.br/assuntos/bolsa-familia/o-que-e>. Acesso em: 28 fev. 2020.

BRASIL. MDS divulga estimativas municipais de atendimento do Bolsa Família. Informe $\mathrm{n}$. 318, 2012. Disponível em: <https://bit.ly/2TiYBY8>. Acesso em: 28 fev. 2020.

BRASIL. Censo 2010. Disponível em: <https://censo2010.ibge.gov.br/resultados.html>. Acesso em: 28 fev. 2020.

BUSS, Paulo Marchiori. Globalização, pobreza e saúde. Ciência \& Saúde Coletiva, Rio de Janeiro, v. 12, n. 6, p. 1575-1589, 2007.

BUSS. Promoção da saúde e qualidade de vida. Ciência \& Saúde Coletiva, v. 5, n. 1, p. 163$177,2000$.

CACCIAMALI, Maria Cristina; TATEI, Fábio; BATISTA, Natália Ferreira. Impactos do Programa Bolsa Família federal sobre o trabalho infantil e a frequência escolar. Revista de Economia Contemporânea, v. 14, n. 2, p. 269-301, 2010.

CAMARGO, Camila Fracaro; CURRALERO, Claudia Regina Baddini; LICIO, Elaine Cristina; MOSTAFA, Joana. Perfil socioeconómico dos beneficiários do programa Bolsa Família. One Pager n. 240, dez. 2013. Disponível em: <https://ipcig.org/pub/port/IPCOnePager240.pdf>. Acesso em: 28 fev. 2020.

CARMO, Michelly Eustáquia; GUIZARDI, Francini. O conceito de vulnerabilidade e seus sentidos para as políticas públicas de saúde e assistência social. Cadernos de Saúde Pública, v. 34, n. 3, 2018.

CHILE. Instituto de Previsión Social. Chile solidario. [2015?]. Disponível em $<$ https://www.ips.gob.cl/servlet/internet/content/1421810829144/chile-solidario>. Acesso em: 28 fev. 2020.

CHZHEN, Yekaterina; FERRONE, Lucia. Multidimensional child deprivation and poverty measurement: Case study of Bosnia and Herzegovina. Social Indicators Research, v. 131, n. 3, p. 999-1014, 2017.

CODES, Ana Luiza Machado de. A trajetória do pensamento científico sobre pobreza: em direção a uma visão complexa. In: INSTITUTO DE PESQUISA ECONÔMICA APLICADA (IPEA). Textos para discussão n. 1332. Brasília, DF: IPEA, 2008. Disponível em: 
$<$ https://www.ipea.gov.br/portal/images/stories/PDFs/TDs/td_1332.pdf>. Acesso em: 28 fev. 2020.

COHEN, Simone Cynamon; BODSTEIN, Regina; KLIGERMAN, Débora Cynamon; MARCONDES, Willer Baumgarten. Habitação saudável e ambientes favoráveis à saúde como estratégia de promoção da saúde. Ciência \& Saúde Coletiva, Rio de Janeiro, vol. 12, n. 1, p. 191-198, 2007.

CORBO, Claudio; PASE, Emerson Luiz. Políticas públicas de transferência de renda na América Latina: uma análise de política comparada. JURIS, v. 24, p. 265-289, 2015.

CORRAR, Luiz J.; PAULO, Edilson; DIAS FILHO, José Maria. Análise multivariada: para os cursos de Administração, Ciências Contábeis e Economia. São Paulo, Atlas, 2009.

DANTAS, Rosana Aparecida Spadoti; SAWADA, Namie Okino; MALERBO, Maria Bernadete. Pesquisas sobre qualidade de vida: revisão da produção científica das universidades públicas do Estado de São Paulo. Revista Latino-Americana de Enfermagem, v. 11, n. 4, p. 532-538, 2003.

ERVIN, Paul A. et al. Multidimensional Poverty in Paraguay: Trends from 2000 to 2015. Social Indicators Research, v. 140, n. 3, p. 1035-1076, 2018.

FAHEL, Murilo; TELES, Letícia Ribeiro; CAMINHAS, Davy Alves. Para além da renda. Uma análise da pobreza multidimensional no Brasil. Revista Brasileira de Ciências Sociais, v. 31, n. 92, p. 1-21, 2016.

FIALHO, Paula Juliana Foltran. O programa Bolsa Família em São Luís (MA) e Belém (PA): um estudo sobre a relação entre gestão local e os efeitos do programa na condição de vida das mulheres. 2007. Dissertação (Mestrado EM Política Social) - Universidade de Brasília, Brasília, DF, 2007.

FRAGA, Luana Santos; BENDER FILHO, Reisoli; CORONEL, Daniel Arruda; VIEIRA, Kelmara Mendes. Uma análise da pobreza multidimensional dos estados brasileiros: construção do índice Fuzzy. Revista Brasileira de Gestão e Desenvolvimento Regional, v. 13, n. 1, 2017.

JANUZZI, Paulo de Martino. Indicadores para diagnóstico, monitoramento e avaliação de programas sociais no Brasil. Revista do Serviço Público, Brasília, DF, v. 56, n. 2, p. 137-160, 2005.

KOLM, Serge-Christophe. Multidimensional Egalitarianisms, The Quarterly Journal of Economics, v. 91, n. 1, p. 1-13, 1977.

LAVINAS, Lena; COBO, Barbara; VEIGA, Alinne. Bolsa Família: impacto das transferências de renda sobre a autonomia das mulheres pobres e as relações de gênero. Revista Latinoamericana de Población, v. 6, n. 10, p. 31-56, 2012.

MACEDO, Márcia dos Santos. Mulheres chefes de família e a perspectiva de gênero: trajetória de um tema e a crítica sobre a feminização da pobreza. Caderno $\mathrm{CRH}$, v. 21, n. 53, p. 385-399, 2008.

MEDELLÍN, Nadin; PRADA, Fernando Sánchez. ¿Cómo funciona Más Familias en Acción? Mejores prácticas en la implementación de Programas de Transferencias Monetarias Condicionadas en América Latina y el Caribe. Banco Interamericano de Desarrollo, 2015. 
MONTOYA, Álvaro José Altamirano; TEIXEIRA, Karla Maria Damiano. Multidimensional poverty in Nicaragua: Are female-headed households better off? Social Indicators Research, v. 132, n. 3, p. 1037-1063, 2017.

NACIONES UNIDAS. CEPAL. División de Desarrollo Social. Base de datos de programas de protección social no contributiva en América Latina y el Caribe. [2011?]. Disponível em: < https://dds.cepal.org/bpsnc/ptc>. Acesso em: 28 fev. 2020.

NAHAS, Markus Vinicius. Atividade física, saúde e qualidade de vida: conceitos e sugestões para um estilo de vida ativo. 3. ed. Londrina, Midiograf, 2003.

NEDER, Henrique; ALVES FILHO, Niemeyer; SOUZA, Sabrina. Acesso à renda e inflação de preços de alimentos no Brasil: análise dos efeitos do programa Bolsa Família. Revista de Economia e Sociologia Rural, v. 53, n. 1, p. 51-70, 2015.

OSORIO, Rafael Guerreiro; SOUZA, Pedro H. G. F. de; SOARES, Sergei S. D.; OLIVEIRA, Luis Felipe Batista de. Perfil da pobreza no Brasil e sua evolução no período 2004-2009. In: INSTITUTO DE PESQUISA ECONÔMICA APLICADA (IPEA). Textos para discussão n. 1647. Brasília, DF: IPEA, 2011. Disponível em: < http://www.ipea.gov.br/portal/images/stories/PDFs/TDs/td_1647.pdf>. Acesso em: 28 fev. 2020.

QUEIROZ, Roberta G. Mendes; CKAGNAZAROFF, Ivan Beck. Inovação no setor público: uma análise do choque de gestão (2003-10) sob a ótica dos servidores e dos preceitos teóricos relacionados à inovação no setor público. Revista de Administração Pública, v. 44, n. 3, p. 679-705, 2010.

RACZYNSKI, Dagmar. Sistema Chile Solidario y la Política de Protección Social de Chile: Lecciones del Pasado y Agenda para el Futuro. Chile: CIEPLAN-Instituto Fernando Henrique Cardoso, 2008.

REGO, Walquiria Leão; PINZANI, Alessandro. Vozes do Bolsa Família: autonomia, dinheiro e cidadania. São Paulo: Unesp, 2014.

RENWICK, Rebecca.; BROWN, Ivan. The center for health promotion's conceptual approach to quality of life. In: RENWICK, Rebecca.; BROWN, Ivan; NAGLER, Mark. (eds.). Quality of life in health promotion and rehabilitation: conceptual approaches, issues and applications. Thousand Oaks: Sage, 1996. p. 75-86.

RESENDE, Anne Caroline Costa; OLIVEIRA, Ana Maria Hermeto Camilo de. Avaliando resultados de um programa de transferência de renda: o impacto do Bolsa-Escola sobre os gastos das famílias brasileiras. Estudos Econômicos, v. 38, n. 2, p. 235-265, 2008.

SALAHUDDIN, Taseer; ZAMAN, Asad. Multidimensional poverty measurement in Pakistan: time series trends and breakdown. The Pakistan Development Review, p. 493-504, 2012.

SANTANA, Jomar Álace. A evolução dos programas de transferência de renda e o Programa Bolsa Família. In: SEMINÁRIO POPULAÇÃO, POBREZA E DESIGUALDADE, 2007, Belo Horizonte. Anais [...]. Belo Horizonte, 2007.

SANTOS, Mariana Cristina Silva; CECCATO, Maria das Graças Braga; DELATORRE, Lucas Rocha; BONOLO, Palmira de Fátima. Programa Bolsa Família e indicadores educacionais em crianças, adolescentes e escolas no Brasil: revisão sistemática. Ciência \& Saúde Coletiva, v. 24, p. 2233-2247, 2019.

SÁTYRO, Natália Guimarães Duarte. Padrões distintos de bem-estar no Brasil: uma análise temporal. Opinião Pública, v. 20, n. 2, p. 219-251, 2014. 
SCHMIDT, Silke; POWER, Mick; BULLINGER, Monika; NOSIKOV, Anatoliy. The conceptual relationship between health indicators and quality of life: results from the cross-cultural analysis of the EUROHIS field study. Clinical Psychology \& Psycho-therapy, Hoboken, v. 2, n. 1, p. 28-49, 2005.

SEN, Amartya. The many faces of gender inequality. New Republic, p. 35-39, 2001.

SEN, Amartya. Inequality Reexamined. Cambridge, MA, 1992.

SEN, Amartya. Commodities and Capabilities. Amsterdam, 1985.

SEN, Amartya. Poverty: An ordinal approach to measurement. Econometrica: Journal of the Econometric Society, v. 44, n. 2, p. 219-231, 1976.

SERRA, Adriana Stankiewicz. Pobreza multidimensional no Brasil rural e urbano. 2017. Tese (Doutorado em Economia) - Universidade Estadual de Campinas, Campinas, SP, 2017.

SIAL, Maqbool H.; NOREEN, Asma; AWAN, Rehmat Ullah. Measuring multidimensional poverty and inequality in Pakistan. The Pakistan Development Review, p. 685-696, 2015.

SILVA, A. M. R.; NEDER, H. D. Abordagem das capacitações: um estudo empírico sobre pobreza multidimensional no Brasil. In: CONFERÊNCIA LATINO AMERICANA E CARIBENHA SOBRE A ABORDAGEM DAS CAPACITAÇÕES E DESENVOLVIMENTO HUMANO, 2010, Porto Alegre. Anais [...]. Porto Alegre, 2010.

SILVA, Maria Ozanira da Silva. O Bolsa Família: problematizando questões centrais na política de transferência de renda no Brasil. Ciência \& Saúde Coletiva, Rio de Janeiro, vol. 12, n. 6, p. 1429-1439, 2007.

VIJAYA, Ramya M.; LAHOTI, Rahul; SWAMINATHAN, Hema. Moving from the household to the individual: Multidimensional poverty analysis. World Development, v. 59, p. 70-81, 2014.

WU, Yichao; QI, Di. A gender-based analysis of multidimensional poverty in China. Asian Journal of Women's Studies, v. 23, n. 1, p. 66-88, 2017.

YÁÑEZ, Ernesto; ROJAS, Ronald; SILVA, Diego. El Bono Juancito Pinto en Bolivia: Un análisis de impacto sobre la educación primaria. Revista Focal: Diálogo, Investigación, Soluciones, p. 1-7, 2011.

\section{NOTAS DE AUTOR}

\section{CONTRIBUIÇÃO DE AUTORIA}

Izete Pengo Bagolin - Concepção. Escolha e Análise de dados Estruturação do manuscrito, redação, revisão e aprovação da versão final do trabalho

Natália Lindemayer -Coleta de dados, cálculo dos indicadores, participação ativa da discussão dos resultados e redação do manuscrito.

Luana dos Santos Fraga - Participação ativa na escolha das dimensões, discussão e análise dos resultados, revisão do manuscrito e aprovação final do trabalho.

\section{FINANCIAMENTO}

Não se aplica.

CONSENTIMENTO DE USO DE IMAGEM

Não se aplica. 
CONFLITO DE INTERESSES

Não há conflito de interesses.

\section{LICENÇA DE USO}

Este artigo está licenciado sob a Licença Creative Commons CC-BY. Com essa licença você pode compartilhar, adaptar, criar para qualquer fim, desde que atribua a autoria da obra.

\section{HISTÓRICO}

Recebido em: 07-03-2019

Aprovado em: 17-04-2020 